\title{
Role of cluster of differentiation 39 (CD39) in the immunosuppressive status associated Acute myeloid leukemia (AML)
}

\author{
Karima A. Mahfouz, Ibraheem M. Bayomi, Lamis M. El-toukhy* \\ Clinical Pathology Department, Al-Azhar University Egypt \\ *Corresponding author: Lamis M. El-toukhy, Clinical pathology department, Al-Azhar University Egypt, \\ Tel 00225398650, E-mail: Lucie.eltokhy@ hotmail.com.
}

\begin{abstract}
Background: CD39 is an integral membrane protein (ectoenzyeme) that phosphohydrolyzes ATP in a Ca ${ }^{2+}$ and $\mathrm{Mg}^{2+}$-dependent fashion to yield AMP, Can be viewed as immunological switch, and is expressed in spleen, thymus, lung, and placenta, and in these organs it is associated primarily with endothelial cells and immune cell populations, such as B cells, NK cells, dendritic cells, Langerhans cells, monocytes, macrophages, mesangial cells, neutrophils, and regulatory T cells. Aim of the study is to assess the expression of $\mathrm{CD} 39$ on $\mathrm{CD} 4^{+} \mathrm{CD} 25^{\text {high }} \mathrm{T}$-reg cells in patients with acute myeloid leukemia to identify its role in immunosuppressive status of AML patients. Methods: Flow cytometric analysis of T-reg cells using CD4 CD25 and CD39 in 60 AML patients and 15 apparently healthy controls with matched age and sex was done. Results: There was a significant difference between cases and controls as regards expression of CD39 on Thelper cells. A highly significant elevation of expression of CD39 has been obtained on T-reg cells in AML patients compared with Controls with increased expression of CD39 on T-reg cells than on helper T cells. Conclusion: CD39 plays a significant role in immunosuppressive status of AML patients particularly with expressing the receptor of $\alpha$ chain of IL-2 (CD25)
\end{abstract}

Key words: Acute Myeloid Leukemia, CD39, Regulatory T Cells

\section{Introduction:}

Acute myeloid leukemia is a complex and heterogeneous hematopoietic tissue neoplasm characterized by rapid expansion of immature myeloid cells in bone marrow and other organs ${ }^{(1)}$ The affected cells undergo an uncontrolled proliferation and impaired differentiation program. Typically, the cells are blocked at various maturation steps and are resistant to cell death ${ }^{(2)}$.

Regulatory $\mathrm{T}$ cells are Foxp $3{ }^{+} \mathrm{CD} 25^{\text {high }} \mathrm{CD} 4^{+} \mathrm{T}$ cells that constitutively express the receptor of $\alpha$ chain of IL-2 (CD25) with diverse immunosuppressive functions. Subsets of $\mathrm{T}$-reg cells include natural T-reg cells $\left(\mathrm{nT}_{\text {regs }}\right)$ that are thymus-derived but undergo further expansion in peripheral tissues, and induced T-reg cells ( $\left.\mathrm{iT}_{\text {regs }}\right)$ that are converted from conventional $\mathrm{T}$ cells $\left(\mathrm{T}_{\text {cons }}\right)$ in the periphery ${ }^{(3)}$.

Both subsets have been shown to suppress autoreactive lymphocytes and thus to limit the magnitude of innate and adaptive immune responses. Accordingly, impaired T-reg function aggravates autoimmune diseases while T-reg mediated immunosuppression may inhibit pathogen clearance and promote chronic infection. In addition to controlling autoimmunity, T-reg cells have been ascribed to have a role as mediators of cancer-related immunosuppression ${ }^{(4)}$.

T-reg cells suppress effector cells and antigen presenting cells either in a contactdependent or -independent manner whereas nTregs can use both mechanisms, iTregs induce immunosuppression through cytokines, including IL-4, IL-10, or TGF- $\beta$. Cell-to-cell interactions can occur between T-reg cells and T-effs with or without APCs. T-reg-to-Teff contact results in the suppression or apoptosis of T- effector cells. On contact, formation of gap junctions occurs between these $2 \mathrm{~T}$ cells. cAMP transferred through the gap from T-reg cells to T-effs suppresses the proliferation of T-effector cells by decreasing IL-2 production and phosphodiesterase 3 inhibitors, which increase cAMP, also increase T-reg cells ${ }^{(5)}$.

In patients with AML, T-reg cells were found to more efficiently hydrolyze adenosine

Received: $13 / 8 / 2018$

Accepted: 29/8/2018 
triphosphate to adenosine compared with Tregs in healthy control patients. It can be speculated that this might increase T-reg cells cAMP levels in patients with AML and might explain the finding that T-reg cells in AML patients are more suppressive than T-reg cells in control patients. Treg cells can also suppress IL-2 mRNA in responding $\mathrm{T}$ cells. Depleting $\mathrm{IL}-2$ from the microenviroment through its highly expressed CD25 is another mechanism to competitively decrease IL-2 available for T-effs ${ }^{(6)}$.

Current treatments for acute myeloid leukemia (AML) have not been changed for several decades and have not resulted in satisfactory outcomes. Modulating the immune system may improve survival in patients with AML ("). Studies indicate that defects in antileukemic effector cells in patients with AML can contribute to the development and persistence of the disease ${ }^{(7)}$. Some Studies ${ }^{(7)}$ have implicated that immune suppressive regulatory $\mathrm{T}$ cells ( $\mathrm{T}$ regs) contribute to a defective antileukemic immune response.

CD39 is an integral membrane protein that phosphohydrolyzes ATP, and less efficiently ADP, in a $\mathrm{Ca}^{2+}$ - and $\mathrm{Mg}^{2+}$-dependent fashion, to yield AMP and is expressed in spleen, thymus, lung, and placenta, and in these organs it is associated primarily with endothelial cells and immune cell populations, such as B cells, natural killer (NK) cells, dendritic cells, Langerhans cells, monocytes, macrophages, mesangial cells, neutrophils, and regulatory T cells ${ }^{(8)}$.

CD39 (with CD73) degrade ATP, ADP, and AMP to adenosine. They can be viewed as "immunological switches" that shift ATP-driven pro-inflammatory immune cell activity toward an anti-inflammatory state mediated by adenosine ${ }^{\left({ }^{(9)}\right.}$.

\section{Aim of the work:}

The study is designed to assess the expression of CD39 on CD4 ${ }^{+} \mathrm{CD} 25^{\text {high }} \mathrm{T}$-reg cells in patients with acute myeloid leukemia to identify its role in immunosuppressive status of AML patients

\section{Methods:}

This Case-Control study was conducted at Clinical Pathology, Medical Oncology and
Hematology Departments, faculty of medicine, AlHussein hospital in the period from November 2016 to January 2018.

The study was carried out on 60 patients with acute myeloid leukemia and 15 apparently healthy controls with matched age and sex.

All patients provided informed consents. The patients were 29 females and 31 males with age range from 17 to 83 years.

\section{All subjects were subjected}

1. Full history taking and clinical examination.

2. Laboratory investigations which includes:

- Complete blood count (CBC) including P.B smear.

- Bone marrow aspiration with examination of Leishman-stained smears laying stress on BM blasts \% and blast morphology (for patients only).

- Flow cytometric analysis of T-reg cells using CD4 CD25 and CD39.

\section{Sample collection}

Two ml of venous blood were obtained from each patient and healthy volunteers by sterile syringes under aseptic conditions to be used for $\mathrm{CBC}$ and flow cytometry.

\section{Methodology}

1. Complete blood count (CBC) using Sysmex SF 3000, Roche Diagnostic $\mathrm{GmbH}$, and Mannheim, Germany).

2. Detection of T-reg cells using CD4 CD25 and CD39 by flow cytometry using FAC scan.

a) Principle In this technique the cells are electronically gated using light scatter parameters (forward scatter reflecting the cell size, and the side scatter reflecting the internal structure of the cell). Antibodies specific for various cellular antigens can be labeled with different fluorochromes that can absorb and emit laser light, allowing simultaneous multicolor flow 
cytometric analysis of two or more cellassociated antigens ${ }^{(\mathbf{1 0})}$.

\section{b) Monoclonal antibodies}

The T-reg cells markers were Fluorescein isocyanate (FITC)-conjugated antihuman CD39 \{eBioscience, USA phycoerythrin (PE)-conjugated antihuman CD25 \{eBioscience, USA $\}$ and Peridinin chlorophyll protein complex (PErCP) - Conjugated anti-human CD4.

c) Methods

i) The surface staining was done by adding $10 \mathrm{ul}$ of each monoclonal antibodie (anti-CD 4 PerCP, anti-CD 25 PE \& anti- CD 39 FITC) to $100 \mathrm{ul}$ of whole anti coagulated blood into the same tube.

ii) The tubes were vortexed and incubated in the dark at room temperature for 30 minutes.

iii) $500 \mathrm{ul}$ of lysing solution was added to the tubes.

iv) The tubes were vortexed and incubated in the dark at room temperature for 10 minutes.

v) The tubes were centrifuged at 1500 rpm for 5 minutes and the supernatant was discarded.

vi) $2 \mathrm{ml}$ of Phosphate buffered saline (PBS) were added to each tube and mixed thoroughly.

vii) The tubes were vortexed and centrifuged at $1500 \mathrm{rpm}$ for 2 minutes and the supernatant was discarded.

viii) Cells were suspended in $500 \mathrm{ul}$ PBS to be ready for analysis.

b) Data acquisition and analysis were performed on software \{cell quest software (BD, San joe, USA) \}.

i) Lymphocytes were gated via their forward and side scatter properties and Treg cells were identified based on their expression of CD4 and CD25. ii) Positive and negative populations of cells were determined using unreactive isotype matched monoclonal antibodies as control for background staining.

iii) To discriminate between $\mathrm{CD} 25^{\text {high }} \mathrm{T}$ regs and $\mathrm{CD} 25^{\text {low }}$ activated effectorsmemory $\mathrm{T}$ cells, we used CD25 expression on non $\mathrm{CD}^{+}$cells as an internal control. They only express intermediate levels of CD25 $\left(\mathrm{CD} 25^{\text {low }}\right)$, whereas $\mathrm{CD}^{+} \mathrm{T}$ cells express CD25 with high (CD25 $\left.5^{\text {high }}\right)$ or intermediate $\left(\mathrm{CD} 25^{\text {low }}\right)$ intensities. Only CD4+ cells expressing CD25 with higher intensities than the internal control cells were included in the gate for $\mathrm{CD} 25^{\text {high }}$ cells. The gate for $\mathrm{CD} 25^{\text {low }}$ cells was set to include cells expressing CD25 at levels above those of the isotype control but at lower expression levels than the CD25 ${ }^{\text {high }}$ cells.

iv) Assess the expression of CD39 on CD $4^{+} \mathrm{CD} 25^{\text {high }} \mathrm{T}$ cells.

\section{Statistical methodology :}

IBM SPSS statistics (V. 19.0, IBM Corp, USA, 2010) was used for data analysis. Data were expressed as Mean \pm standard deviation (SD) for quantitative parametric measures in addition to median for quantitative non-parametric measures and both number and percentage for categorized data.

- The level of significance was stated at 0.05 to be accepted.

- $\mathrm{P}$ value $>0.05$ was considered non significant result.

- $\mathrm{P}$ value $<0.05$ was considered significant result.

- $\quad$ P value $<0.01$ or $<0.001$ was considered a highly significant result.

\section{Statistical tests used in the study:}

1- Student t test: used for Comparison between two independent mean groups for parametric data. 
2- Chi-square test: to study the association between each 2 variables or comparison between 2 independent groups as regards the categorized data.

3- Mann-Whitney test: was done for quantitative variables for not normally distributed and $\mathrm{p}$ - value $<0.05$ was considered significant.

4- Pearson correlation (r) test: to study the possible association between each two variables among each group for nonparametric data and $\mathrm{p}$ - value $<0.05$ was considered significant.
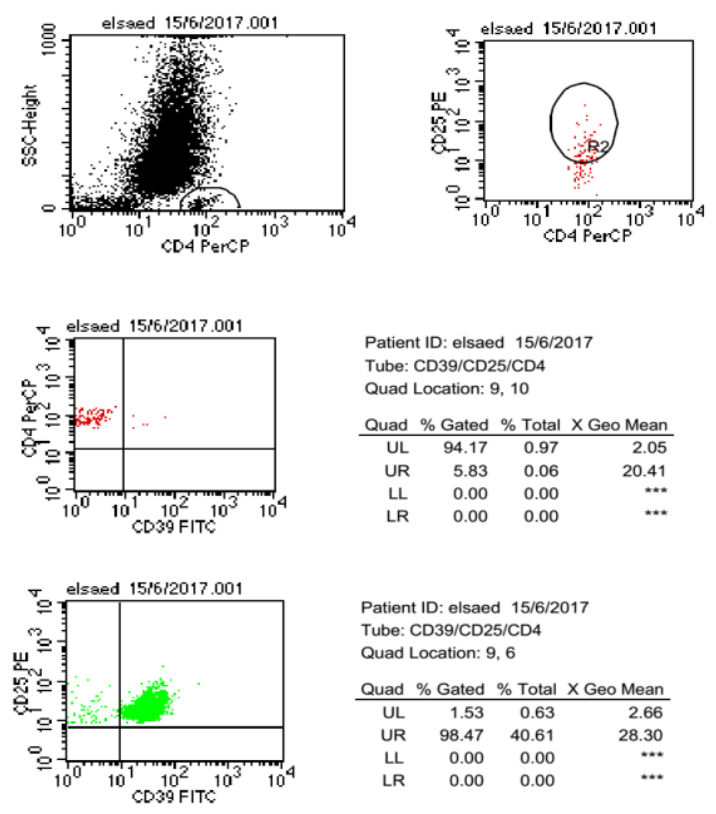

Patient ID: elsaed 15/6/2017 Tube: CD39/CD25/CD4 Quad Location: 9, 6
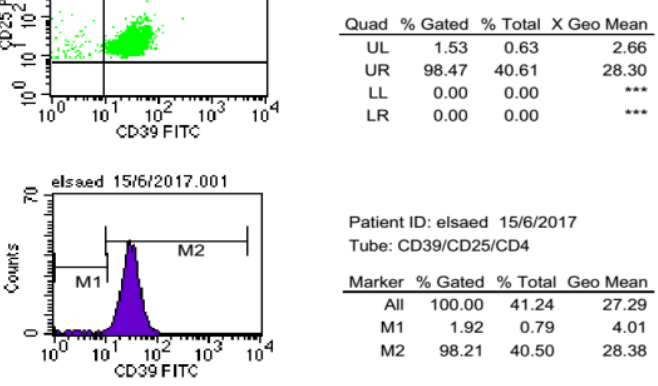

Patient ID: elsaed 15/6/2017 Tube: CD39/CD25/CD4

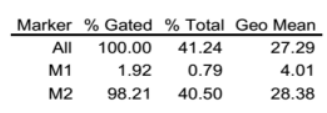

Figure (1): Histogram (1): Flow cytometric detection of CD39 on T-reg cells and T- helper cells in AML patient showing increased expression of CD39 on T-reg cells (98.2\%) than on T-helper cells $(5.83 \%)$.
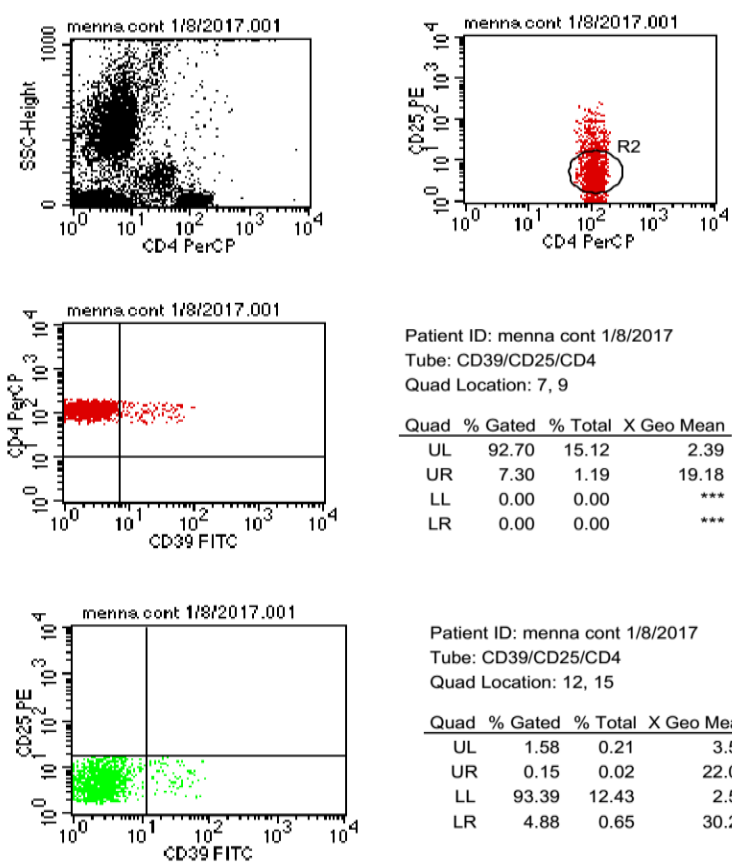

Patient ID: menna cont 1/8/2017 Tube: $\mathrm{CD} 39 / \mathrm{CD} 25 / \mathrm{CD} 4$

Quad Location: 12,15
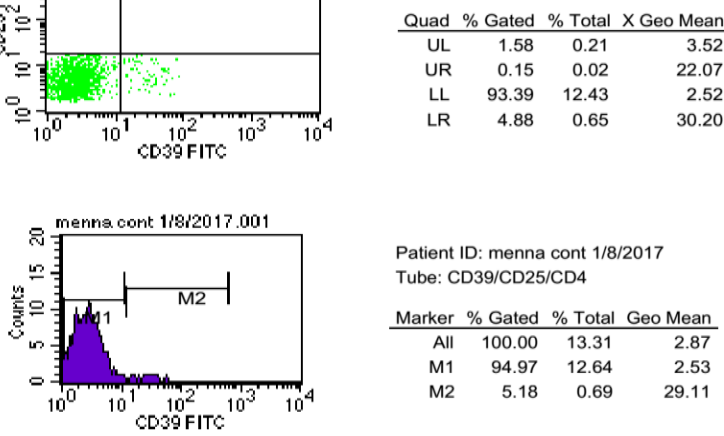

Patient ID: menna cont 1/8/2017 Tube: CD39/CD25/CD4

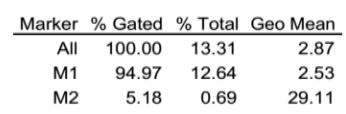

Figure (2): Histogram (2): Flow cytometric detection of CD39 on T-reg cells and T-helper cells in apparently healthy control showing decreased expression of CD39 on T-reg cells (5.18\%) and on T-helper cells $(7.3 \%)$.

\section{Results:}

Table (1): Demographic data f AML patients and control group.

\begin{tabular}{|c|c|c|c|c|c|c|}
\hline & \multicolumn{2}{|c|}{$\begin{array}{l}\text { Cases } \\
n=60\end{array}$} & \multicolumn{2}{|c|}{$\begin{array}{c}\text { Controls } \\
n=15\end{array}$} & $\mathrm{t}$ - test & $P$ value \\
\hline $\begin{array}{c}\text { Age } \\
\text { (years) }\end{array}$ & \multirow{2}{*}{\multicolumn{2}{|c|}{$\begin{array}{c}17-83 \\
43.8 \pm 14.1\end{array}$}} & \multirow{2}{*}{\multicolumn{2}{|c|}{$\begin{array}{c}18-70 \\
41.9 \pm 16.5\end{array}$}} & \multirow[b]{2}{*}{0.45} & \multirow[b]{2}{*}{0.65} \\
\hline $\begin{array}{l}\text { Range } \\
\bar{X}+S D\end{array}$ & & & & & & \\
\hline Sex & No & $\%$ & $\mathrm{No}$ & $\%$ & $\mathrm{X}^{2}$ & $P$ \\
\hline Male & 31 & 51.7 & 8 & 53 & \multirow{2}{*}{0.0237} & \multirow{2}{*}{0.981} \\
\hline Female & 29 & 48.3 & 7 & 47 & & \\
\hline
\end{tabular}

This table (1) shows: 
Role of cluster of differentiation 39 (CD39) in the immunosuppressive status associated Acute...

- No significant difference between the two studied groups as regards age.

$>$ No significant difference between the two studied groups as regards sex

Table (2): Comparison of $\mathrm{CD}^{2} 9^{+} \mathrm{CD} 4^{+}(\%)$ (CD39 on T-helper cells) and CD39+ ${ }^{+} \mathrm{CD} 4^{+} \mathrm{CD} 25^{+}$ (\%) (CD39 on T-reg cells) between AML patients and controls.

\begin{tabular}{|l|c|c|c|c|}
\hline & $\begin{array}{c}\text { Cases } \\
\mathrm{n}=60\end{array}$ & $\begin{array}{c}\text { Controls } \\
\mathrm{n}=15\end{array}$ & $\begin{array}{c}\mathrm{M} \\
\mathrm{W}\end{array}$ & $\begin{array}{c}\mathrm{P}- \\
\text { value }\end{array}$ \\
\hline $\begin{array}{l}\text { CD39CD4 (\%) } \\
\text { Range }\end{array}$ & $\begin{array}{c}2.8-98.02 \\
25.1 \pm 21 .\end{array}$ & $\begin{array}{c}5.1-26.27 \\
12.8 \pm 5.9\end{array}$ & & \\
& 5.38 & 0.036 \\
$\mathrm{X} \pm \mathrm{SD}$ & 18.15 & 12.1 & & \\
Median & & & & \\
\hline $\begin{array}{c}\text { CD39CD4CD25(\% } \\
)\end{array}$ & $16.14-$ & $5-23.53$ & & \\
Range & 99.78 & & & \\
& $58.7 \pm 22.4$ & $10.98 \pm 5$. & 34.9 & $<0.00$ \\
$\bar{X} \pm$ SD & 57.69 & 9.4 & & 1 \\
Median & & & \\
\hline
\end{tabular}

This table (2) shows: a comparative study revealing a significant difference between cases and control as regards expression of CD39 on Thelper cells. But there is a highly significant elevation of expression of CD39 on T-reg cells in AML patients compared with Controls.

Table (3) Correlation between Blast cells no. in peripheral blood and $\mathrm{CD} 39^{+} \mathrm{CD} 4^{+}(\%)$

\begin{tabular}{|c|c|c|c|}
\hline & $\mathrm{r}$ & $\mathrm{P}$ & Sig \\
\hline Blasts vs & & & \\
$\mathrm{CD} 39^{+} \mathrm{CD} 4^{+}$ & 0.13 & $>0.05$ & NS \\
\hline
\end{tabular}

This table (3) shows Correlation between Blast cells count in peripheral blood and expression of CD39 on T helper cells and it reveals no significant correlation.

Table (4) Correlation between Blast cells no. in peripheral blood and $\mathrm{CD} 39^{+} \mathrm{CD} 4{ }^{+} \mathrm{CD} 25^{+}(\%)$

\begin{tabular}{|c|c|c|}
\hline & $\mathrm{r}$ & \\
\hline Blasts vs & -0.06 & \\
$\mathrm{CD} 39^{+} \mathrm{CD} 4^{+} \mathrm{CD} 25^{+}$ & & \\
& & \\
\hline
\end{tabular}

This table (4) shows Correlation between Blast cells count in peripheral blood and expression of CD39 on Treg cells and it reveals an inverse correlation not reached to the significant level.

Table (5) Correlation between Blast cells (\%) in B.M and $\mathrm{CD} 39^{+} \mathrm{CD}^{+}(\%)$

\begin{tabular}{|c|c|c|c|}
\hline & $\mathrm{r}$ & $\mathrm{P}$ & $\mathrm{Sig}$ \\
\hline Blasts vs. & & & \\
CD39+CD4 & 0.08 & $>0.05$ & $\mathrm{NS}$ \\
\hline
\end{tabular}

This table (5) shows Correlation between Blast cells (\%) in Bone marrow and expression of CD39 on T helper cells and it reveals no significant correlation.

Table (6) Correlation between Blast cells (\%) in B.M and $\mathrm{CD}^{3} 9^{+} \mathrm{CD}^{+} 4 \mathrm{CD} 25^{+}(\%)$

\begin{tabular}{|c|c|c|c|}
\hline & $\mathrm{R}$ & $\mathrm{p}$ & $\mathrm{Sig}$ \\
\hline Blasts vs. & & & \\
$\mathrm{CD}^{+} 9^{+} \mathrm{CD} 4^{+} \mathrm{CD} 25^{+}$ & -0.12 & $>0.05$ & $\mathrm{NS}$ \\
\hline
\end{tabular}

This table (6) shows Correlation between Blast cells (\%) in bone marrow and expression of CD39 on Reg $\mathrm{T}$ cells and it reveals an inverse correlation not reached to the significant level.

\section{Discussion:}

Current treatments for acute myeloid leukemia (AML) have not been changed for several decades and have not resulted in satisfactory outcomes. Modulating the immune system may improve survival in patients with AML. T-reg cells have been ascribed to have a role as mediators of cancer- related immunosuppression ${ }^{(6)}$.

Studies (7) indicate that defects in antileukemic effector cells in patients with AML can contribute to the development and persistence of the disease. Studies (7) have implicated that immune suppressive regulatory $\mathrm{T}$ cells (T-regs) contribute to a defective antileukemic immune \begin{tabular}{l|l} 
responsep & Sig
\end{tabular}

CD39 is an integral membrane protein expressed in spleen, thymus, lung, and placenta, and in these organs it is associated primarily with 
endothelial cells and immune cell populations, such as B cells, natural killer (NK) cells, dendritic cells, Langerhans cells, monocytes, macrophages, mesangial cells, neutrophils, and regulatory $\mathrm{T}$ cells. This ectoenzyme phosphohydrolyzes ATP, and less efficiently ADP, in a $\mathrm{Ca}^{2+}$ - and $\mathrm{Mg}^{2+}$ dependent fashion, to yield AMP ${ }^{(8)}$.

CD39 (with CD73) degrade ATP, ADP, and AMP to adenosine. They can be viewed as "immunological switches" that shift ATP-driven pro-inflammatory immune cell activity toward an anti-inflammatory state mediated by adenosine ${ }^{\left({ }^{(9)}\right.}$.

In patients with AML, T-reg cells were found to more efficiently hydrolyze adenosine triphosphate to adenosine compared with Tregs in healthy control patients. It can be speculated that this might increase T-reg cells cAMP levels in patients with AML and might explain the finding that T-reg cells in AML patients are more suppressive than T-reg cells in control patients. Treg cells can also suppress IL-2 mRNA in responding $\mathrm{T}$ cells. Depleting $\mathrm{IL}-2$ from the microenviroment through its highly expressed CD25 is another mechanism to competitively decrease IL-2 available for T-effs ${ }^{(6)}$

The present study was carried out on two groups: the patient group included 60 patients with denovo AML who aged from 17 to 83 years with mean \pm SD $(43.8 \pm 14.1)$. There were 29 females and 31 males. The control group included 15 apparently healthy individuals aged from 18 to 70 years old with mean \pm SD $(41.9 \pm 16.5)$. There were 7 females and 8 males.

Regarding a comparative study of CD39 expression on T-helper and T-reg cells in patients suffering from de novo AML\& apparently normal controls revealed a significant difference between cases and control as regards expression of CD39 on T- helper cells. However there was a highly significant elevation of expression of CD39 on Reg. T- cells in AML patients compared with Controls with increased expression of CD39 on reg $\mathrm{T}$ cells than on helper T cells suggesting role of CD 39 in immunosuppressive status of AML patients.

These results were in accordance with a previous study (11) that revealed a significant difference between AML patients and controls as regards expression of CD39 on Reg. T- cells.
Studying expression of CD39 on T-reg cells in head and neck squamous cell carcinoma ${ }^{(\mathbf{1 2})}$ the results revealed a significant difference between head and neck squamous cell carcinoma (HNSCC) and controls.

In another Study ${ }^{(13)}$ CD39 was found to be expressed and active on CLL cells. The level of CD39 activity correlates with the stage of the disease. A decrease in CD39 activity was correlated with worsening of disease. These findings suggest that CD39 may be involved in the pathogenesis and prognosis of CLL.

Our study revealed no significant correlation between Blast cells count in peripheral blood and expression of CD39 on T helper cells. On the other hand an inverse correlation existed though non significant level between Blast cells count in peripheral blood and expression of CD39 on T-reg cells, As well no significant correlation existed between Blast cells (\%) in Bone marrow and expression of CD39 on T helper cells though an inverse correlation not reached to the significant level existed between Blast cells (\%) in bone marrow and expression of CD39 on T-reg cells.

Regarding the age and gender, the results are comparable to that of other studies (14) (15) (2) who demonstrated that median age of the patients was 51, 48 and 42 years; respectively and male to female ratio was $285 / 215,70 / 53$ and $48 / 34$; respectively.

In another study ${ }^{(\mathbf{1 6})}$, the results revealed that distribution of affected males and females is nearly equal, at all ages, The incidence of AML is higher in males than in females with male to female ratio of 1.1:1.0. In contrary to the results ${ }^{(17)}$ which stated that AML is more common in males than females with a ratio of 1.18:0.84 (the same findings announced by American cancer society estimates 2014).

In conclusion, the present study shows that CD39 is an immunosuppressive though not a good prognostic marker in AML. However the prognostic value has to be verified by follow up of cases on a larger scale. AML is more common in males than in females.

\section{References:}


Role of cluster of differentiation 39 (CD39) in the immunosuppressive status associated Acute...

1. Döhner H, Weisdorf DJ, Bloomfield CD (2015): Acute Myeloid Leukemia, N Engl J Med., 373(12):1136-52.

2. Pezzi A, Moraes L, Valim V, Amorin B et al. (2012): DNMT3A Mutations in Patients with Acute Myeloid Leukemia in South Brazil. Adv Hematol., doi:10.1155/2012/697691.

3. Yadav M , Stephan S, Bluestone JA (2013): Peripherally induced tregs - role in immune homeostasis and autoimmunity, Front Immunol., 4:232.

4. Sander FE, Nilsson M, Rydström A et al. (2017): Role of regulatory $T$ cells in acute myeloid leukemia patients undergoing relapse-preventive immunotherapy, Cancer Immunol Immunother ., 66(11): 1473-1484.

5. Feng G, Nadig SN, Bäckdahl L et al .(2011) : Functional regulatory $\mathrm{T}$ cells produced by inhibiting cyclic nucleotide phosphodiesterase type 3 prevent allograft rejection. Sci Transl Med., 3(83):83ra40.

6. Ustun C, Miller JS, Munn DH, Weisdorf DJ et al. (2011): Regulatory T cells in acute myelogenous leukemia: is it time for immunomodulation?. Blood, 118(19):508495.

7. Zhou Q, Munger ME, Highfill SL et al.(2010) :Program death-1 signaling and regulatory $\mathrm{T}$ cells collaborate to resist the function of adoptively transferred cytotoxic $\mathrm{T}$ lymphocytes in advanced acute myeloid leukemia.:Blood,116(14):2484-93

8. Antonioli L, Colucci R, La Motta $\mathrm{C}$ et al.(2012): Adenosine deaminase in the modulation of immune system and its potential as a novel target for treatment of inflammatory disorders. Curr. Drug. Targets, 13:842-86.

9. Beavis PA, Stagg J, Darcy PK et al.(2012): CD73: a potent suppressor of antitumor immune responses .Trends Immunol.,33(5):231-7
10. Rahman $\mathbf{F}(\mathbf{2 0 0 6})$ :Introduction to Flowcytometry.J. Clin. Invest., 45:345-361.

11. Dulphy $\mathrm{N}$, Henry $\mathrm{G}$, Hemon $\mathrm{P}$ et al. (2014): contribution of CD39 to the immunosuppressive microenviroment of acute myeloid leukemia at diagnosis, $\mathrm{Br} \mathbf{J}$ hematol.,165(5):722-740.

12. Schuler PJ, Schilling B, Harasymczuk M et al.(2012): Phenotypic and functional characteristics of ATP-hydrolysing CD4+CD39+FOXP3+ and CD4+CD39+FOXP3negT-cell subsets in patients with cancer, Eur J Immunol .,42(7): 1876-188.

13. Pulte D, Olson KE, Broekman MJ et al. (2007) :CD39 activity correlates with stage and inhibits platelet reactivity in chronic lymphocytic leukemia, J transl med.,5:23.

14. Hou H, Kuo Y, Liu C, Chou W et al. (2011): DNMT3A mutations in acute myeloid leukemia stability during disease evolution and the clinical implications. Blood, 23: 541-549.

15. Renneville A, Boissel N, Niboure I et al. (2012): Prognostic significance of DNA methyltransferase $3 \mathrm{~A}$ mutations in cytogenetically normal acute myeloid leukemia: a study by the Acute Leukemia French Association. Leukemia,26: 12471254.

16. El Hefni A. , Abu Taleb F ,Hadhoud K et al.(2013): Prognostic Assessment of PGlycoprotein over Expression in Refractory and / or Relapsed Acute Myeloid Leukemia and Response to Cyclosporine A, Life Sci J ., 10(1):1427-1436.

17. Chang $\mathrm{F}$, Shamsi TS and Waryah AM et al. (2016): Clinical and Hematological Profile of Acute Myeloid Leukemia (AML) Patients of Sindh, J Hematol Thrombo Dis.,4(2):239 